\title{
Differential extracellular enzyme production in colonies of Coriolus versicolor, Phlebia radiata and Phlebia rufa: effect of gaseous regime
}

\author{
NiA A. White and LyNNE BodDY* \\ School of Pure and Applied Biology, University of Wales College of Cardiff, PO Box 915, Cardiff CF1 3TL, UK
}

(Received 27 July 1992; accepted 24 August 1992)

\begin{abstract}
The effects of different gaseous regimes on the growth rate and extracellular enzyme location in vitro of colonies of Phlebia radiata, Phlebia rufa and Coriolus versicolor are reported. The two Phlebia species showed similar growth, extracellular enzyme and pH responses to gaseous composition $\left(\mathrm{N}_{2}, \mathrm{O}_{2}\right.$ and $\left.\mathrm{CO}_{2}\right)$, but the responses of $C$. versicolor differed. Whilst maximum extension rates were obtained for all species under atmospheric gaseous composition, maximum biomass production occurred at $5 \%$ (v/v) $\mathrm{O}_{2}$ with $20 \%(\mathrm{v} / \mathrm{v}) \mathrm{CO}_{2}$ for the Phlebia species and at $5 \% \mathrm{O}_{2}$ with $60 \% \mathrm{CO}_{2}$ for $C$. versicolor. The Phlebia species had a coenocytic margin (5-6 mm width) under atmospheric conditions, which increased in width with increasing percentage of $\mathrm{CO}_{2}$. Laccase and peroxidase activity were present throughout the septate region, but not in the coenocytic zone. With $C$. versicolor laccase and peroxidase activities appeared throughout the colony, but were more intense in the peripheral region, under all gaseous regimes. A laser densitometer, normally used to visualize proteins on electrophoresis strips, was used to estimate profiles of biomass and laccase- $\alpha$-naphthol activity within colonies. Surface $\mathbf{p H}$ changed little in colonies of $C$. versicolor but dropped by over $1 \mathrm{pH}$ unit from the margin inwards with the Phlebia species. The significance of these results is discussed in terms of ecological strategy and developmental versatility.
\end{abstract}

\section{Introduction}

The mycelium, the vegetative form of the majority of wood-decay fungi, operates during colonization of wood within a spatially and temporally dynamic environment. Consequently it exhibits spatial and temporal differences in metabolic functioning, which are directly influenced by its developmental state (Rayner \& Coates, 1987). Fungi exhibit considerable developmental plasticity, being able to adopt and switch between a variety of distinct 'functional modes' (Gregory, 1984), i.e. programmed morphogenetic cycles which confer versatility on the fungus (Rayner et al., 1987), and hence adapt its functioning to local episodic environmental pressures. It is not, however, clear how much of this developmental plasticity is attributable to direct interactions between micro-environmental parameters and metabolic functioning, and how much to selection of different modes by pre- or post-translational switch mechanisms. Even on relatively homogeneous laboratory media interconvertible mycelial polymorphisms are frequently evident, including yeast-mycelial transitions, slow-dense/fasteffuse morphs, and aerial versus appressed or submerged growth (Rayner \& Coates, 1987).

\footnotetext{
* Author for correspondence. Tel. 0222 874000; fax 0222874305.
}

There is some evidence of differences in extracellular enzyme production between different modes. For example, the basidiomycete Hymenochaete corrugata has two strikingly different colony morphs: a woolly, white form producing extensive aerial mycelium, and an appressed pigmented form with laccase and tyrosinase activity, associated with more decayed wood regions (Sharland et al., 1986). The basidiomycete Phellinus tremulae has an appressed phenoloxidase-producing, pigmented form which extends more slowly and grows at higher temperatures than the 'aerial' form, which produces peroxidase but not phenoloxidase (Hiorth, 1965; Niemela, 1977). Rigidoporus microporus produces a mycelial form which is tolerant of poor aeration, produces laccase and may be responsible for development within wood, and a form which produces mycelial cords responsible for superficial ectotrophic spread, but which does not produce laccase (Boisson, 1968; Geiger et al., 1976). The zygomycete Mortierella isabellina has an appressed sporulating form on malt agar, which forms fan-shaped sectors of fast-growing, non-sporulating mycelium when the colony has been subjected to grazing by Collembola (Onychiurus armatus); protease activity was higher and activity of an additional serine protease was detected in the switched sector (Hedlund et al., 1991). 
Different morphogenetic modes are also sometimes consistently exhibited in an exact spatio-temporal pattern within individual thalli. Thus, colonies of the white-rot basidiomycetes Phlebia radiata and Phlebia rufa have a peripheral growing front composed of sparsely branched, rapidly extending, coenocytic, appressed, non-anastomosing and non-combative hyphae, followed by a mycelial system of highly branched, septate, submerged and aerial hyphae, with clamps if mating has occurred (Boddy \& Rayner, 1983a). The hyphae at the margin represent a mode adapted to rapid extension, which in nature may lead to early establishment in wood (primary resource capture), whilst the septate mode is adapted to replacing other fungi, exploitation of a resource and defence of territory (Boddy \& Rayner, $1983 a$ ). Thus, the different regions could be expected to exhibit different enzymic capacities. This might be further affected by gaseous regime, since aeration is suggested to be critical in the development of Phlebia species (Boddy \& Rayner, 1983a) and results in morphological changes in other fungi (Schanel, 1976; Tabak \& Cooke, 1968). Moreover, gaseous regime within decomposing wood varies both spatially and temporally, and a high concentration of $\mathrm{CO}_{2}$ and low concentration of $\mathrm{O}_{2}$ relative to atmospheric air often exists (Hintikka \& Korhonen, 1970; Carrodus \& Triffett, 1975).

These observations suggest profoundly differing physiological and morphological patterns among and within a range of white-rot fungi, correlated with different colonization strategies and developmental characteristics. However, the majority of fungal extracellular enzyme studies have involved growth in liquid culture, where spatial and temporal heterogeneity akin to that on solid substrata in the natural environment is lost (e.g. Kirk \& Farrell, 1987). Consequently, the general validity of conclusions drawn from these studies is unclear, and there is urgent need for more developmentally and ecologically directed biochemical investigations. Improved knowledge of the control of development by way of abiotic environmental cues is essential for a better understanding of the ecology and biotechnological manipulation of these organisms. To further this, we have examined the growth characteristics and the spatial location of certain enzymes within Phlebia and Coriolus (=Trametes) versicolor colonies grown under different gaseous regimes.

\section{Methods}

Organisms and culture conditions. Heterokaryons of Phlebia radiata (Fr.), Phlebia rufa (Fr. M.P. Christ.) and Coriolus versicolor (L. ex. Fr.), from the departmental culture collection, were maintained on $2 \%(w / v)$ malt extract agar (MEA : $20 \mathrm{~g}$ Fisons spray malt, $15 \mathrm{~g}$ Difco agar, in 1 litre distilled water) at $25^{\circ} \mathrm{C}$, in the dark.
In all experiments $9 \mathrm{~cm}$ diameter triple-vented Petri dishes (Phoenix Biomedical Products) containing $20 \mathrm{ml} 2 \%$ (w/v) MEA were prepared using a calibrated Accuramatic filler, and inoculated aseptically at their centres with plugs $(9 \mathrm{~mm}$ diam.) of each culture, removed with a sterile cork borer, from the margins of actively growing colonies. Plates were incubated in the dark, in gas jars containing a Petri dish of water to maintain high humidity, at $25^{\circ} \mathrm{C}$ under a variety of gaseous regimes $\left(5 \%, \mathrm{v} / \mathrm{v}, \mathrm{O}_{2}\right.$ with $0,20,60$ and $90 \%, \mathrm{v} / \mathrm{v}, \mathrm{CO}_{2}$, and $60 \% \mathrm{O}_{2}$ with $20 \%$ $\mathrm{CO}_{2}$, the remainder being $\mathrm{N}_{2}$ in each case), the gaseous mixtures being renewed daily. All experiments were performed on colonies of diameter $7 \mathrm{~cm}$, irrespective of age.

Colony growth. Mean radial extension rates were determined by making daily measurements of two diameters on each plate; this was performed in triplicate. Also, the entire, intact, agar plus colony, was removed from the Petri dish using a spatula, and the absorbance at $632.8 \mathrm{~nm}$ was measured along the diameter using a laser densitometer (Ultrascan, LKB Bromma) in conjunction with a Warwick Computer Control system software, running on a BBC B micro-computer, interfaced with the densitometer. The areas of the traces produced were estimated using an image analysis system which employed a Synapse frame store and Semper 6P software (Synoptics, Cambridge), installed in a Dell system 300 micro computer. This gave an estimated profile (Fig. 1) and relative values of colony biomass.

Assessment of cultural characteristics. The terminologies of Stalpers (1978) and Boddy \& Rayner (1983a) were used to describe gross morphology and cultural characteristics observed by light microscopy. The presence or absence of coenocytic hyphae, aerial hyphae with cystidioles, and clamp connections was ascertained in samples taken from different positions on the plates.

Measurement of surface $\mathrm{pH}$. Surface $\mathrm{pH}$ was measured at nine points approximately $5 \mathrm{~mm}$ apart, from centre to plate periphery using a Dulas Engineering digital pH meter (Dulas Engineering, Aberystwyth Instruments), with a flat-tipped, Active ion surface electrode (Russell Electrodes), at ambient temperature on uninoculated plates of MEA and on triplicate plates with colonies of approximately $7 \mathrm{~cm}$ diameter. The position of the colony periphery was noted.

Extracellular enzyme production. The following biochemical tests were performed in a similar manner to that described by Poppe \& Welvaert (1983), by flooding plates with appropriate test solutions, and incubating under atmospheric gaseous regime, so as not to affect the titre of the assays. The presence or absence and location of enzyme activity was noted. All tests were performed in triplicate.

(i) The Nobles test employed $1.67 \%$ (w/v) Gum Guaiac (Sigma) in $96 \%$ (v/v) ethanol (BDH). A blue coloration developing within $2 \mathrm{~h}$ indicated extracellular oxidase production, suggesting the ability to degrade lignin (Nobles, 1965).

(ii) The laccase- $\alpha$-naphthol test employed $1.44 \%(w / v) \alpha$-naphthol (Analar, BDH) in $96 \%$ ethanol. A purple coloration developing within $2 \mathrm{~h}$ indicated production of extracellular laccase (EC 1.10.3.2; $p$-diphenol :oxygen oxidoreductase), suggesting the ability to oxidize p-diphenols (Metzler, 1977; Stalpers, 1978; Prillinger \& Molitoris, 1981). The absorbance at $632.8 \mathrm{~nm}$ was measured along the same colony diameter before and after staining, using the Ultrascan laser densitometer/Warwick computer control system. The areas under these traces minus the areas under the respective biomass traces (Fig. 1) were estimated using the image analysis system. When calibrated using different dilutions of a standard laccase from Pyricularia oryzae (Sigma), this gave a semi-quantitative profile of laccase activity.

(iii) The laccase-guaiacol test employed $1.24 \%(w / v)$ guaiacol (Sigma) in $96 \%$ ethanol. A reddish coloration developing within $2 \mathrm{~h}$ indicated extracellular laccase production as in the laccase- $\alpha$-naphthol test (Molitoris, 1978; Boidin, 1951). 

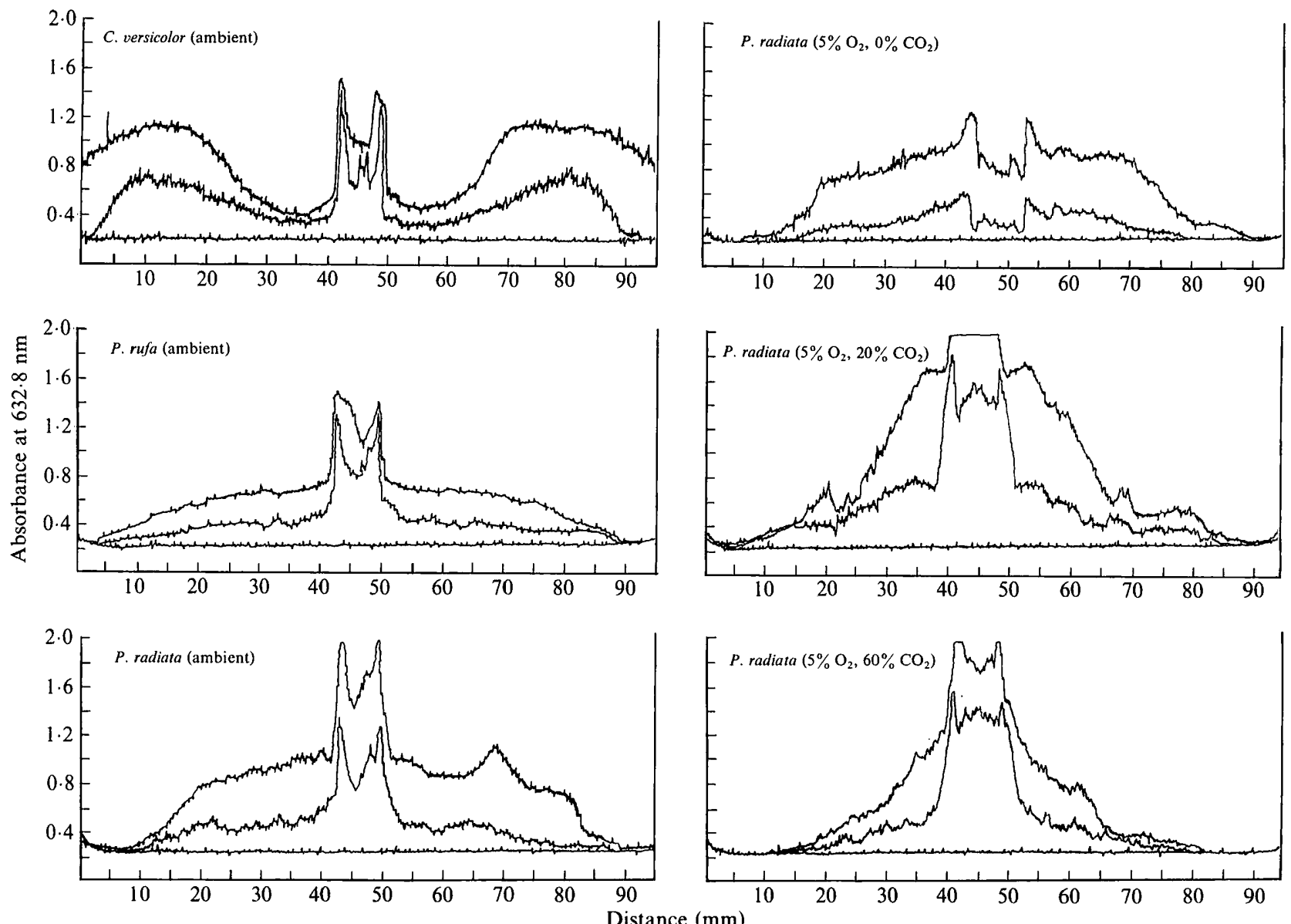

Fig. 1. Estimated profiles of biomass (middle profile) and laccase- $\alpha$-naphthol (highest profile) activity (absorbance at $632 \cdot 8 \mathrm{~nm}$ ) of $C$. versicolor, $P$. radiata and $P$. rufa incubated on $2 \%$ MEA (lowest profile) under different gaseous regimes.

(iv) The tyrosinase test employed $1.08 \%(w / v) p$-cresol in $96 \%$ ethanol. An orange-brown coloration developing within $12 \mathrm{~h}$ indicated tyrosinase (EC 1.10.3.1; $o$-diphenol :oxygen oxidoreductase) activity, suggesting the ability to hydroxylize monophenols and oxidize $o$-diphenols (Long \& Alben, 1978; Stalpers, 1978; Molitoris, 1978).

(v) The peroxidase test employed equal parts of $0.4 \%(v / v) \mathrm{H}_{2} \mathrm{O}_{2}$ (Analar, BDH) and $1 \%(\mathrm{v} / \mathrm{v})$ pyrogallol (Analar, $\mathrm{BDH})$ in water. $\mathrm{A}$ yellow-brown coloration developing within $2 \mathrm{~h}$ indicated peroxidase (EC 1.11.1.7) activity (Stalpers, 1978).

(vi) The acid phosphatase test employed equal parts of $1 \%(w / v) \alpha-$ naphthol phosphate (Sigma) and a $1 \%(w / v)$ solution in acetone (BDH) of Fast Red ITR Base (Sigma). A violet to purple coloration developing within $12 \mathrm{~h}$ indicated activity of phosphatase (EC 3.1.3.2; ophosphoric-monoester phosphohydrolase, acid pH optimum) (Stalpers, 1978).

(vii) The esterase test employed equal parts of $1 \%(w / v) \alpha$-naphthol acetate (Sigma) and $1 \%(w / v)$ acetone solution of Fast Red ITR Base. A purplish coloration developing within $12 \mathrm{~h}$ indicated esterase (EC 3.1.-.-) activity, suggesting the ability to hydrolyse esters (Stalpers, 1978).

\section{Results}

\section{Extension rate and colony biomass}

Maximum extension rates of all three species were obtained under an atmospheric gaseous regime, $P$. rufa

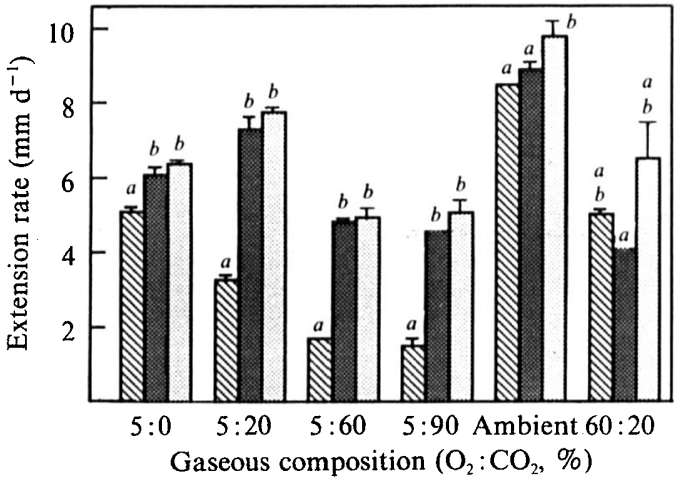

Fig. 2. Extension rates of $C$. versicolor $(\mathbb{Q}), P$. radiata (圈) and $P$. rufa $($ in) incubated under different gaseous regimes. Data for each gaseous regime with the same letter above are not significantly different $(P>$ 0.05), using one-way Anova and Fisher PLSD tests.

always having greater extension rates than $P$. radiata and C. versicolor (Fig. 2). Extension rates for both Phlebia species showed similar responses to gaseous composition. At $5 \% \mathrm{O}_{2}$, maximum extension occurred with $20 \% \mathrm{CO}_{2}$. At $20 \% \mathrm{CO}_{2}$, increasing $\left[\mathrm{O}_{2}\right]$ from 5 to $60 \%$ resulted in a reduction in colony extension rate. 
C. versicolor, by contrast, showed decreased extension rates with increased $\left[\mathrm{CO}_{2}\right]$, and at $20 \% \mathrm{CO}_{2}$, increased $\left[\mathrm{O}_{2}\right]$ stimulated colony extension rate.

Biomass production by the Phlebia species showed similar but less marked responses to gaseous composition; however, $P$. radiata always produced greater biomass than $P$. rufa, their maxima being obtained at $5 \%$ $\mathrm{O}_{2}, 20 \% \mathrm{CO}_{2}$ (Fig. 3). C. versicolor produced more biomass than either Phlebia species under all conditions. With $5 \% \mathrm{O}_{2}$, biomass production by $C$. versicolor was proportional to $\left[\mathrm{CO}_{2}\right]$, up to a maximum at $5 \% \mathrm{O}_{2}, 60 \%$

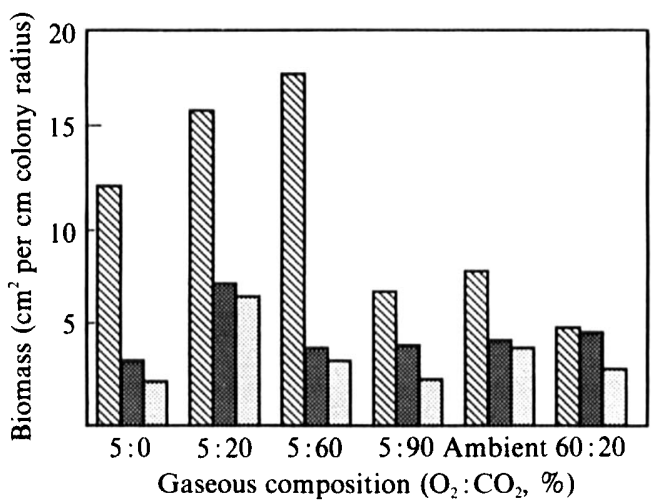

Fig. 3. Biomass production of $C$. versicolor $(\mathbb{\mathbb { N }}), P$. radiata (圈) and $P$. rufa (䔞) incubated under different gaseous regimes.
$\mathrm{CO}_{2}$, but then declined at $5 \% \mathrm{O}_{2}, 90 \% \mathrm{CO}_{2}$. At $20 \%$ $\mathrm{CO}_{2}$, increasing $\left[\mathrm{O}_{2}\right]$ resulted in a decrease in biomass production by all three species.

\section{Cultural characteristics}

C. versicolor grew as a white woolly colony, whose morphology changed conspicuously with different gaseous regimes (Fig. 4). The two Phlebia species grew as cottony, cream-white sparse colonies with little aerial mycelium, $P$. radiata having relatively more aerial mycelium than $P$. rufa. The colony morphologies of both Phlebia species changed less conspicuously with incubation in different gaseous regimes; slightly increased aerial mycelium production around the central inoculum was noticed in $P$. radiata at $\left[\mathrm{CO}_{2}\right]>20 \%$, and in $P$. rufa, at $\left[\mathrm{CO}_{2}\right]>60 \%$. All three species possessed appressed colony margins. $P$. rufa had $3-6 \mu \mathrm{m}$ wide marginal hyphae, $1.5-2.5 \mu \mathrm{m}$ aerial hyphae, and 5-6 $\mu \mathrm{m}$ submerged hyphae, with thin to sometimes thickened walls. $P$. radiata produced $2-7 \mu \mathrm{m}$ marginal hyphae, 1.5$3.5 \mu \mathrm{m}$ aerial hyphae, with thin to thickened walls, and 5-6 $\mu \mathrm{m}$ submerged hyphae, with irregular swellings. At $5 \% \mathrm{O}_{2}$ with $0 \% \mathrm{CO}_{2}$ the hyphae of $C$. versicolor $(3-6 \mu \mathrm{m}$ wide) showed what appeared to be either irregular thickening of the cell wall, or shrinking of the protoplasm
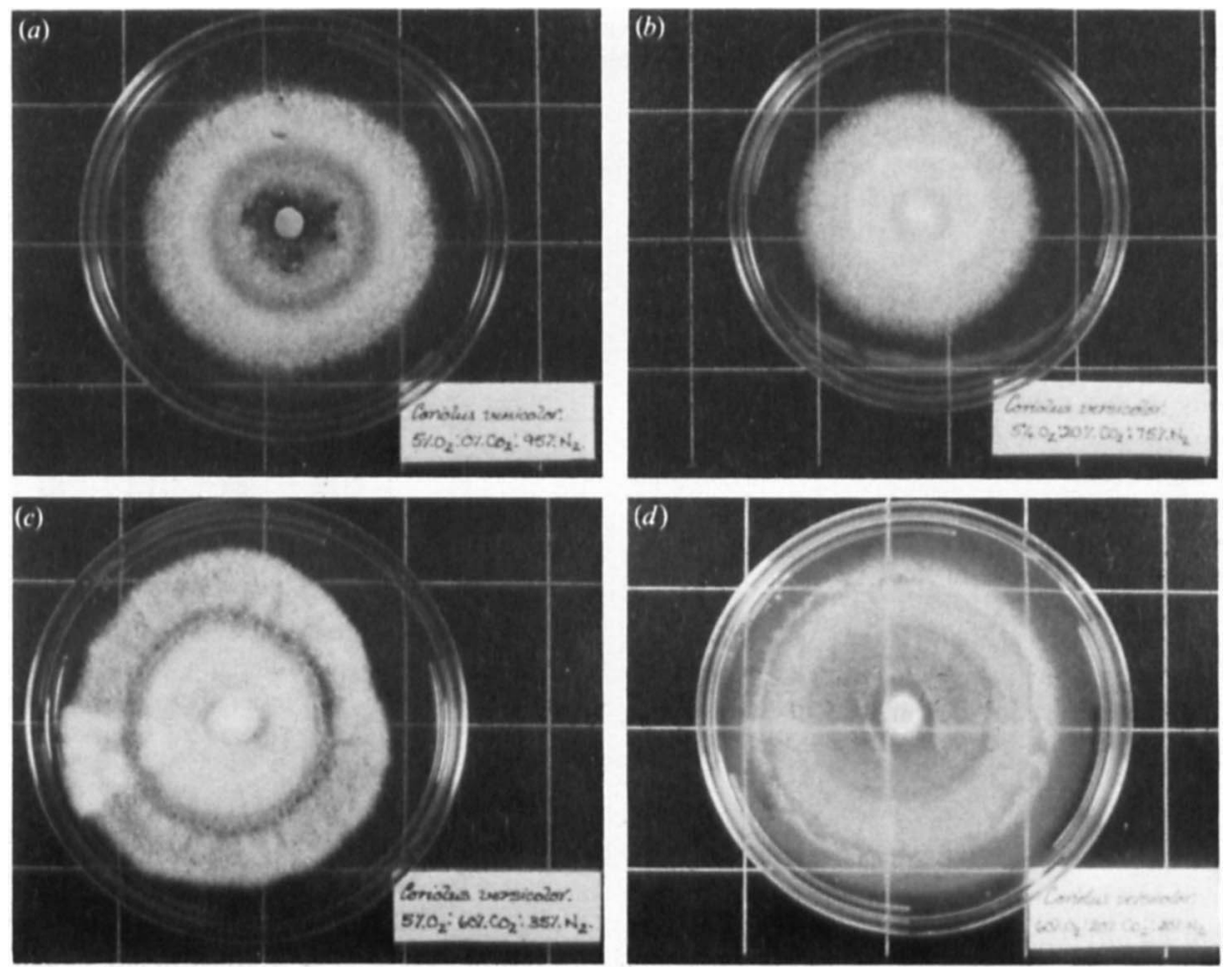

Fig. 4. Colony morphologies of $C$. versicolor incubated on $2 \% \mathrm{MEA}$, at $25{ }^{\circ} \mathrm{C}$, under different gaseous regimes: $(a) 5 \% \mathrm{O}_{2}$ with $0 \% \mathrm{CO}_{2}$, (b) $5 \% \mathrm{O}_{2}$ with $20 \% \mathrm{CO}_{2},(c) 5 \% \mathrm{O}_{2}$ with $60 \% \mathrm{CO}_{2}$, and $\left(\right.$ d) $60 \% \mathrm{O}_{2}$ with $20 \% \mathrm{CO}_{2}$, the remainder being nitrogen in each case. 

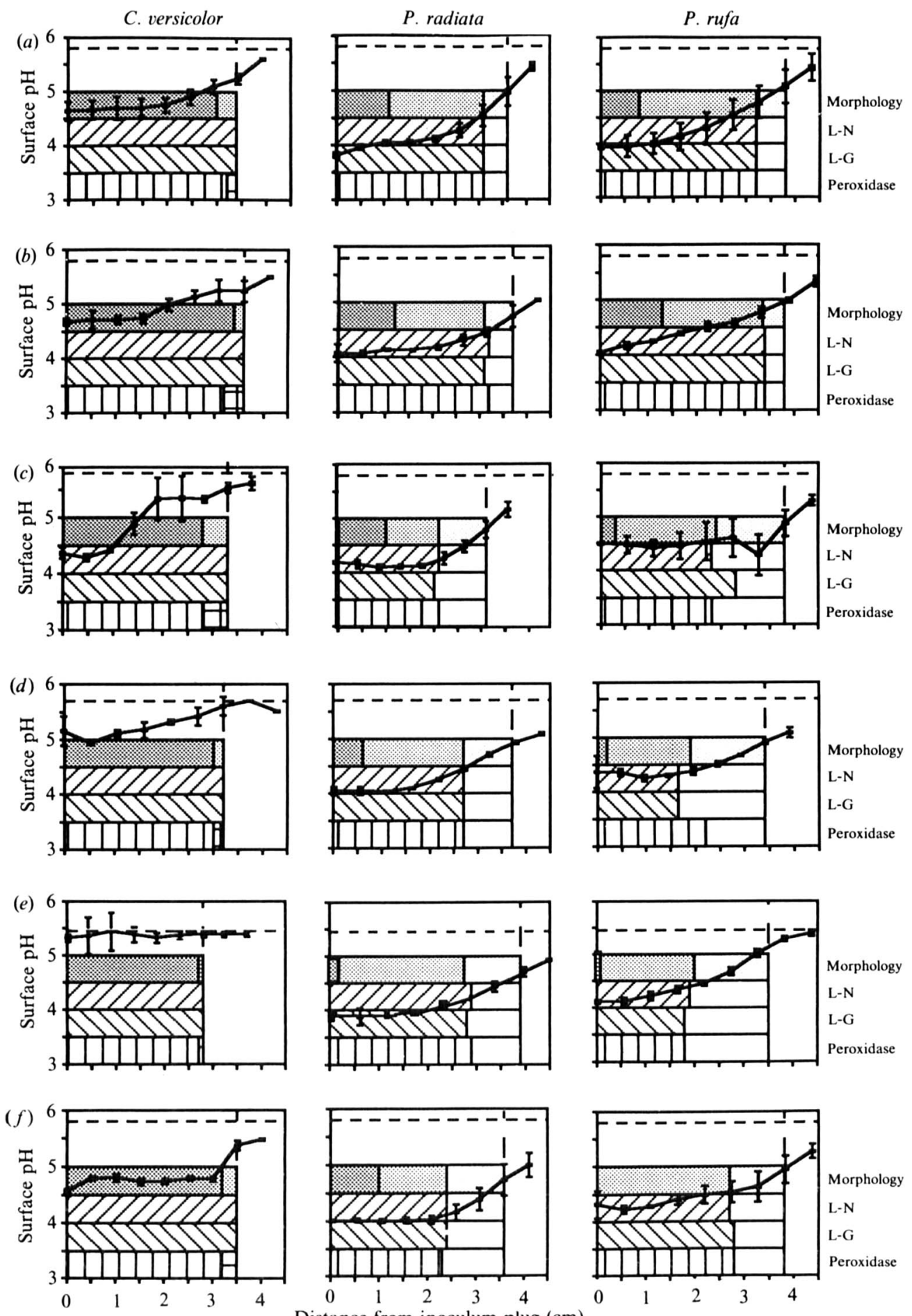

Fig. 5. Mycelial morphology ( $\square$, coenocytic; 궁, septate; 夙, septate with clamps), surface pH (----, before growth; $\square$, after growth)

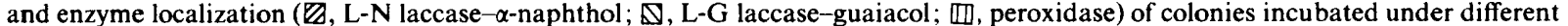
gaseous regimes. A more intense reaction is indicated by 柬. (a) Ambient; (b) $5 \% \mathrm{O}_{2}, 0 \% \mathrm{CO}_{2} ;(c) 5 \% \mathrm{O}_{2}, 20 \% \mathrm{CO}_{2} ;(d) 5 \% \mathrm{O}_{2}, 60 \%$ $\mathrm{CO}_{2} ;(e) 5 \% \mathrm{O}_{2}, 90 \% \mathrm{CO}_{2} ;(f) 60 \% \mathrm{O}_{2}, 20 \% \mathrm{CO}_{2}$. 


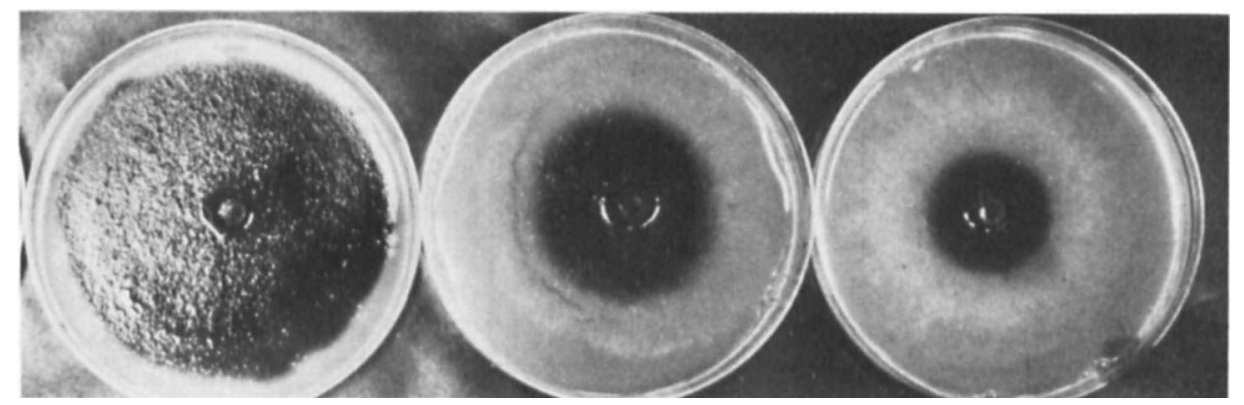

Fig. 6. Location of laccase- $\alpha$-naphthol activity (darker regions) within colonies of $P$. rufa incubated on $2 \%$ MEA at $25{ }^{\circ} \mathrm{C}$, and $5 \% \mathrm{O}_{2}$ with (from left to right) $0 \%, 20 \%$ and $90 \% \mathrm{CO}_{2}$.

away from the cell wall, and at $60 \% \mathrm{O}_{2}$ with $20 \% \mathrm{CO}_{2}$ the hyphal tips appeared to curl around themselves. $C$. versicolor hyphae exhibited much branching at $5 \% \mathrm{O}_{2}$ with 0,20 and $60 \% \mathrm{CO}_{2}$, and little branching at $5 \% \mathrm{O}_{2}$ with $90 \% \mathrm{CO}_{2}$. P. rufa showed more frequent branching at $5 \% \mathrm{O}_{2}$ with $20 \% \mathrm{CO}_{2}$ than it did at $5 \% \mathrm{O}_{2}$ with $0 \%$ $\mathrm{CO}_{2}$ or at $5 \% \mathrm{O}_{2}$ with $60 \% \mathrm{CO}_{2}$. When incubated at $5 \%$ $\mathrm{O}_{2}$ with $20 \% \mathrm{CO}_{2}, P$. rufa produced small bud-like structures on its hyphae.

The coenocytic margin was $5 \mathrm{~cm}$ wide in $P$. radiata, and $6 \mathrm{~cm}$ wide in $P$. rufa under atmospheric conditions, and in both Phlebia species the width increased with increase in $\left[\mathrm{CO}_{2}\right]$, irrespective of $\mathrm{O}_{2}$ concentration (Fig. 5). At $5 \% \mathrm{O}_{2}$, the septate region with clamp connections decreased in width with increasing $\left[\mathrm{CO}_{2}\right]$. At $5 \% \mathrm{O}_{2}$, fewer clamp connections appeared to be produced by $P$. rufa with increasing $\left[\mathrm{CO}_{2}\right]$, and no clamp connections were produced by either Phlebia species at $5 \% \mathrm{O}_{2}, 90 \%$ $\mathrm{CO}_{2}$. P. rufa also produced no clamp connections at $60 \%$ $\mathrm{O}_{2}$ with $20 \% \mathrm{CO}_{2}$. When incubated at $5 \% \mathrm{O}_{2}$ with 0,20 , 60 or $90 \% \mathrm{CO}_{2}$, and at $60 \% \mathrm{O}_{2}$ with $20 \% \mathrm{CO}_{2}$, hyphae of C. versicolor became vacuolated. Hyphae of both Phlebia species were vacuolated at $5 \% \mathrm{O}_{2}$ with $0 \% \mathrm{CO}_{2}$, and those of $P$. rufa were also vacuolated at $60 \% \mathrm{O}_{2}$ with $20 \%$ $\mathrm{CO}_{2}$.

\section{$p H$ and extracellular enzyme production under different gaseous regimes}

The surface $\mathrm{pH}$ of $2 \%$ MEA prior to inoculation was $5.82 \pm 0.01$ (mean \pm SEM). This dropped to between $\mathrm{pH} 4.5$ and $\mathrm{pH} 5.0$ at the margin of $P$. radiata and $P$. rufa colonies, but altered little in this region with $C$. versicolor, under all gaseous regimes (Fig. 5). The $\mathrm{pH}$ dropped to about 4.0 within $2.0 \mathrm{~cm}$ of the inoculum plug in $P$. radiata, and to between 4.0 and 4.5 in $P$. rufa, but with $C$. versicolor the $\mathrm{pH}$ rarely dropped below 4.5 , and often remained above $5 \cdot 0$.

The Nobles test gave uniform positive results, and the tyrosinase, acid phosphatase and esterase tests gave

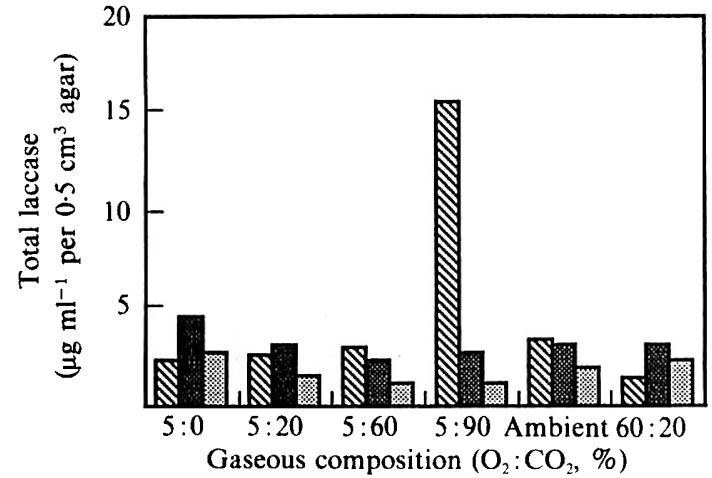

Fig. 7. Total laccase concentration of $C$. versicolor $(\mathbb{Q}), P$. radiata (图) and $P$. rufa (T) incubated under different gaseous regimes.

negative results in all situations studied. A purple or red coloration developed when $\alpha$-naphthol or guaiacol was applied to the growing mycelium of all species under all conditions, indicating the presence of laccase (Fig. 6). Both laccase tests and the peroxidase test indicated coincident localization of enzyme activity (Fig. 5). Coenocytic regions in colonies of Phlebia species exhibited negative reactions to the laccase- $\alpha$-naphthol, laccase-guaiacol and peroxidase tests. A region of intense peroxidase and laccase activity was found in the outer few millimeters of $C$. versicolor colonies where few septa or clamp connections were apparent. Total laccase concentration varied under different gaseous regimes (Fig. 7). P. radiata always showed greater enzyme activities than $P$. rufa, both species having maximum activities at $5 \% \mathrm{O}_{2}, 0 \% \mathrm{CO}_{2}$. C. versicolor showed maximum activity at $5 \% \mathrm{O}_{2}, 90 \% \mathrm{CO}_{2}$.

\section{Discussion}

In nature, $P$. rufa appears to be a pioneer invader of attached, light suppressed, branches and trunks of oak (Quercus sp.), causing little decay, whilst $P$. radiata and C. versicolor are ubiquitous invaders of attached, felled or 
fallen decomposing angiosperm wood (Boddy \& Rayner, $1983 a, b)$. The growth and extracellular enzyme activities observed in this cultural study are at least partly correlated with the ecological roles of these fungi in nature. The more rapid extension rates of $P$. rufa, under all conditions, correlate with the role of primary colonizer, where rapid occupation of territory is of ecological advantage (Boddy \& Rayner, 1983a). Tolerance of $P$. rufa to elevated $\left[\mathrm{CO}_{2}\right]$ might also be advantageous in initial colonization of recently functional sapwood, where $\left[\mathrm{CO}_{2}\right]$ is high and $\left[\mathrm{O}_{2}\right]$ low, relative to ambient (Carrodus \& Triffett, 1975). The poorer tolerance of $C$. versicolor to elevated $\left[\mathrm{CO}_{2}\right]$ correlates with its later appearance in fungal communities decaying attached branches (Boddy \& Rayner, 1983 b). C. versicolor did, however, allocate relatively more 'effort' to production of aerial biomass under increased atmospheric $\mathrm{CO}_{2}$ regimes, but exactly how this relates to growth in wood is not clear.

The trends in growth responses of both Phlebia species to gaseous composition are broadly similar to those of a range of wood-decay basidiomycetes (Gunderson, 1961; Hintikka \& Korhonen, 1970), a slight elevation of $\left[\mathrm{CO}_{2}\right]$ having a stimulating effect on growth, whereas a higher $\left[\mathrm{CO}_{2}\right]$ inhibited mycelial growth. $C$. versicolor, by contrast, showed decreased extension rates with increased $\left[\mathrm{CO}_{2}\right]$ - similar to observations by Schanel (1976). The extension rates of species and their corresponding biomass production did not show a consistent reciprocal or proportional relationship, concurring with the findings of Hintikka \& Korhonen (1970).

The concentric-banded appearance of $C$. versicolor colonies cultivated under various gaseous regimes was also observed by Schanel (1976), and the slightly increased aerial mycelium production noted around central Phlebia inocula under relatively high $\left[\mathrm{CO}_{2}\right]$ was described for other species by Schanel (1976). Lack of change in hyphal diameter under different gaseous regimes suggests little or no intracellular interference of the fungal plasma membrane proton pump. Increased branching frequency of $C$. versicolor and $P$. rufa hyphae appeared to correlate with increasing colony biomass, and the little branching of $C$. versicolor hyphae at $5 \% \mathrm{O}_{2}$ with $90 \% \mathrm{CO}_{2}$ might possibly reflect an increased deployment of energy incorporated into laccase production. The bud-like structures produced on $P$. rufa hyphae at $5 \% \mathrm{O}_{2}$ with $20 \% \mathrm{CO}_{2}$ have been noted previously $(\mathrm{H}$. Rawles, A. D. M. Rayner \& L. Boddy, unpublished), and similar changes in hyphal morphology have been seen in other basidiomycetes incubated at $20-30 \% \quad \mathrm{CO}_{2}$ (Schanel, 1976). It has been tentatively suggested that such structures, yeast-like forms or mycelial fragments might act as propagules, dispersing the fungus in the sapstream of functional xylem (Boddy \& Rayner, 1983b).
Many $C$. versicolor hyphae were vacuolated under all regimes except ambient, and those of Phlebia species under regimes with a $\mathrm{O}_{2}: \mathrm{CO}_{2}$ ratio $>1$. It has been suggested that vacuolated hyphae may be a morphological expression of internal $\mathrm{pH}$ regulation of carbonic acid during generally stressed growth, aiding internal regulation of $\mathrm{pH}$ by acting as a sink or source of protons (Jennings, 1988).

Any inhibition of growth or metabolism in our experiments probably resulted at least partly from the $\mathrm{pH}$ effects of both dissolved carbon dioxide and bicarbonate, as opposed to a shift from aerobic to anaerobic metabolism (i.e. from the tricarboxylic acid cycle to the Embden-Meyerhof-Parnas pathway). The general increase in surface $\mathrm{pH}$ of colonies of C. versicolor, and the approximately consistent surface $\mathrm{pH}$ values of Phlebia colonies incubated at increasing $\left[\mathrm{CO}_{2}\right]$, may confirm their oxidative metabolism, and that increasing $\left[\mathrm{CO}_{2}\right]$ did not cause a shift to fermentative metabolism.

Production of laccase and peroxidase by all three fungal species was not unexpected since they are whiterot fungi, hence capable of depolymerizing lignocellulosic complexes (e.g. Harkin \& Obst, 1973; Stalpers, 1978). $P$. radiata always showed greater enzyme activities (correlated with greater aerial mycelium and biomass production) than $P$. rufa, which possibly reflects the greater decay capacity of the former in the field (Boddy \& Rayner, $1983 \mathrm{~b}$ ). That both species had maximum activities at $5 \% \mathrm{O}_{2}, 0 \% \mathrm{CO}_{2}$ may suggest that it is the $\mathrm{O}_{2}: \mathrm{CO}_{2}$ ratio that is significant for laccase production, as opposed to an increased $\left[\mathrm{O}_{2}\right]$. Laccase activity was apparently stimulated by increased $\left[\mathrm{O}_{2}\right]$ in $P$. rufa but not in $P$. radiata, yet Hatakka \& Uusi-Rauva (1983) found that $\mathrm{O}_{2}$ strongly enhanced lignin degradation in wood by the latter. However, laccase is not the only enzyme to be implicated in the decomposition of the lignocellulose complex (Kirk \& Farrell, 1987; Evans et al., 1991), and the activities of other enzymes may have been stimulated. Vermousek \& Schanel (1973) and Schanel (1976) provided evidence for increased activity of certain extracellular enzymes under a suitable elevated concentration of carbon dioxide. In the present study, total laccase activity produced by $C$. versicolor was four times greater under $5 \% \mathrm{O}_{2}$ with $90 \% \mathrm{CO}_{2}$ than under any other gaseous regime. The elevated laccase levels in $C$. versicolor were correlated with the slowest extension rate and low biomass production, and there is some evidence that rate and/or extent of mycelial out-growth from wood and wood decay rate are inversely related (Levine, 1965; Thompson \& Rayner, 1982; Wells \& Boddy, 1990). However, the high laccase activity in $C$. versicolor may simply be an artefact of experimental procedure, since tests were performed when colonies had reached a certain size irrespective of age. 
The elevated levels of laccase activity in $C$. versicolor under a high $\mathrm{CO}_{2}$ regime may be at least partly related to hydrogen ion concentration. Here, a consistent value of pH 5 was obtained across the surface of the plate, whereas under other regimes and all regimes for Phlebia species, the $\mathrm{pH}$ was much lower. Whilst relatively few enzyme studies have included measurements of $\mathrm{pH}$, it is clear that different wood-decay enzymes have different pH optima for activity. For example, the $\mathrm{pH}$ optimum for a Lentinus edodes laccase was $\mathrm{pH} 4$, with negligible activity below pH 3 or above pH 5.5 (Leatham \& Stahmann, 1981); those of Podospora anserina laccases II and III were respectively 7.5 and 6.0 (Molitoris, 1978); that of Phanerochaete chrysosporium 'ligninase' was pH 4.5, the same as for lignin breakdown (Glenn \& Gold, 1985), whereas crude lignin peroxidase had a $\mathrm{pH}$ optimum of 3.1 (Kirkpatrick \& Palmer, 1989); those of oxidase and peroxidase of $P$. radiata were between $\mathrm{pH} 3$ and 4.5 (Niku-Paavola et al., 1988).

In liquid culture, maximum laccase activity was detected after $3 \mathrm{~d}$ for $P$. radiata, but lignin peroxidase activity did not appear until after laccase activity had reached a maximum and begun to decline (Kantelinen $e t$ $a l .$, 1989). This early appearance of laccase is common among laccase-producing cultures of fungi (Bollag \& Leonowicz, 1984; Kantelinen et al., 1989), although in some cases its production is induced by the presence of appropriate substrates (Mayer \& Harel, 1979); Kaarik (1965) stated that malt extract induced laccase secretion into the medium at an early stage of growth. Here, on solid media, there is no evidence of laccase production beginning prior to peroxidase production (i.e. laccase was not produced any closer to the colony margin than was peroxidase). In fact, with $C$. versicolor, peroxidase production was often greatest at the colony margin. However, the peroxidase test employed was not specific for lignin peroxidase, hence the results are equivocal. Nevertheless, Wosten et al. (1990) described secretion of lignin peroxidase initially in the central colony region, associated with growth of secondary hyphae arising in the central secreting area of $P$. chrysosporium.

Despite extensive investigation, the exact biological functions of phenoloxidases (laccase and peroxidase) have not yet been irrefutably determined, and therefore few conclusions regarding their production can be made. However, their association with different cultural morphologies may be discussed in view of previously postulated function or consequence. Laccase has been implicated in numerous processes, including morphogenesis (Devi et al., 1989; Wood et al., 1990), detoxification of phenolics (Moss, 1984), modification of protolignin and lignin (Morohoshi et al., 1989; Katayama et al., 1989), and control of lignin and cellulose degradation (Westermark \& Eriksson, 1974; Lundquist \& Kristers- son, 1985; Morpeth \& Jones, 1986). However, such patterns of enzyme production may simply reflect a physiological need for changes in carbon flow associated with new physiological activities (Paterson, 1988). It has also been speculated that some form of metabolic coupling to phenoloxidases occurs in fungi during periods when endogenous metabolism cannot keep up with cellular demands (Leatham \& Stahmann, 1981). Lignin peroxidase is definitely a key enzyme of depolymerization of lignin, and its production by $P$. radiata (Hatakka \& Tervila-wilo, 1986; Niku-Paavola et al., 1988; Katelinen et al., 1989) and C. versicolor (Dodson et al., 1987; Jonsson et al., 1987) has previously been reported.

The aerial mycelium is a clear example of hyphal differentiation since these hyphae must acquire a hydrophobic surface. For their growth, they are dependent on resources retrieved from the submerged mycelium (Wessels, 1991), and act as a means of freeing growing hyphae from constraints imposed by the chemical or physical boundaries derived from the substratum (e.g. staling products and poor aeration). Aerial mycelia can differentiate into fruiting structures, and Esser $e t$ al. (1984) suggested that the basis for the cue responsible for the transition from vegetative to reproductive growth involves elicitation of programmed 'senescence' pathways, associated with activation of phenoloxidase systems and melanization. The phenoloxidase activity exhibited within aerial-mycelium-producing zones of colonies studied during the present investigation might therefore be associated with a deceleration of appressed or submerged hyphal extension, and a switch to senescence pathways in this region.

Furthermore, Rayner et al. (1987) suggested that a series of superimposable switch mechanisms control the outcome of contrasting patterns of morphogenesis (such as branching and extension, diffuse and coherent growth, juvenility and senescence) rather than genetic heterogeneity, conferring on the individual developmental versatility enabling it to span the heterogeneous, changing and often discontinuous niches it occupies in nature. The mechanisms controlling switching between distinctive mycelial modes are not understood: A. D. M. Rayner (1991, personal communication) has hypothesized that the dysfunction of mitochondrial Krebscycle-associated primary metabolism represents a way of switching cells into secondary metabolism, by activating or derepressing, for example, the shikimic acid and acetate pathways, and phenoloxidase enzyme systems. Resultant production of highly hydrophobic compounds (which might result in or from production of aerial mycelium) and free radicals would then have important effects on mycelial morphology and physiology. The phenoloxidase activity unequivocally associated with the 
septate mycelium in this study might therefore result from a switch to secondary metabolism, from the primary metabolism probably adopted by the coenocytic mycelium of Phlebia species.

The consistent lack of peroxidase and laccase activities in the coenocytic regions of both Phlebia species, which unlike in the study of Boddy \& Rayner (1983a) was usually wider in $P$. rufa than in $P$. radiata, supported the suggestion that this mycelium may be responsible for utilization of readily available carbon compounds rather than those in the lignocellulosic complex, and that they facilitate exploration and coverage of domain (Boddy \& Rayner, 1983a). However, the width of the coenocytic zone appears to be directly correlated with the degree of abiotic stress (temperature, water potential, gaseous regime, and $\mathrm{pH}$ apart from very alkaline regimes) rather than with rapid extension rate (White, 1992). That laccase and peroxidase production is confined to the mode which is septate and has aerial mycelium, rather than being related to a certain age or distance from the colony margin, is indicated by, for example, the fact that the coenocytic zone increased in width under elevated $\mathrm{CO}_{2}$ regimes and the location of the zone where laccase and peroxidase were absent was coincident with this. Also, with $C$. versicolor, which does not exhibit the astatocoenocytic behaviour of Phlebia spp., there was no region where laccase and peroxidase activity were absent. There may be cross-reactivity between the laccase- $\alpha$-naphthol, laccase-guaiacol and peroxidase tests, and therefore the coincident regions of activity may merely indicate regions of oxidative activity. The probable presence of both $\mathrm{H}_{2} \mathrm{O}_{2}$-producing and -consuming enzymes (such as glucose oxidase and catalase) makes the distinction between laccase and peroxidase difficult (Koenigs, 1974).

We acknowledge the joint support of the Science and Engineering Research Council and ICI Biological Products Research Group, especially Dr S. C. Taylor. We wish to thank Dr A. C. Peters for his assistance with the image analysis.

\section{References}

BODDY, L. \& RAYNER, A. D. M. (1983a). Mycelial interactions, morphogenesis and ecology of Phlebia radiata and Phlebia rufa from oak. Transactions of the British Mycological Society 80, 437-448.

BODDY, L. \& RAYNER, A. D. M. (1983b). Ecological roles of basidomycetes forming decay communities in attached oak branches. New Phytologist 93, 177-188.

Boidin, J. (1951). Recherche de la tyrosinase et laccase chez les basidiomycetes en culture pure. Revue de Mycologie 16, 173-197.

Borsson, C. (1968). Mise en évidence de deux phases mycéliennes successives au cours du développement du Leptoporus lignosus (K1.) Heim. Comptes Rendus de l'Académie des Sciences, Série D 266, 112115.

BollaG, J.-M. \& Leonowicz, A. (1984). Comparative studies of extracellular laccases. Applied and Environmental Microbiology 48, 849-854.
Carrodus, B. B. \& TRIfFetT, A. C. K. (1975). Analysis of composition of respiratory gases in woody stems by mass spectrometry. New Phytologist 74, 243-246.

Devi, C. C., Tripathi, R. K. \& Ramaiah, A. (1989). pH-dependent interconvertible forms of mushroom tyrosinase with different kinetic properties. Pigment Cell Research 2, 8-13.

Dodson, P. J., Evans, C. S., Harvey, P. J. \& Palmer, J. M. (1987) Production and properties of an extracellular peroxidase from Coriolus versicolor which catalyses $\mathrm{C}_{\alpha}-\mathrm{C}_{\beta}$ cleavage in a lignin model compound. FEMS Microbiology Letters 42, 17-22.

ESSER, K. (1984). Senescence in Podospora anserina and its implication for genetic engineering. In The Ecology and Physiology of the Fungal Mycelium, pp. 343-352. Edited by D. H. Jennings \& A. D. M. Rayner. Cambridge: Cambridge University Press.

Evans, C. S., Gallagher, I. M., ATKey, P. T. \& Wood, D. A. (1991) Localization of degradative enzymes in white-rot decay of lignocellulose. Biodegradation 2, 93-106.

Geiger, J. P., NANDRIS, D. \& Goujon, M. (1976). Activité des laccases et des peroxidases au sein de vacines d'Hévéa attaquées par le pourridié blanc (Leptoporus lignosus (K1.) Heim). Physiologie Végétale 14, 271-282.

GlenN, J. K. \& Gold, M. H. (1985). Purification and characterization of an extracellular $\mathrm{Mn}$ (II)-dependent peroxidase from the lignindegrading basidiomycete Phanerochaete chrysosporium. Archives of Biochemistry and Biophysics 242, 329-341.

GREGORY, P. H. (1984). The fungal mycelium: an historical perspective. Transactions of the British Mycological Society 82, 1-11.

GUNDERSON, K. (1961). Growth of Fomes annosus under reduced oxygen pressure and the effect of carbon dioxide. Nature, London $190,649$.

HARKIN, J. M. \& OBST, J. R. (1973). Syringaldazine, an effective reagent for detecting laccase and peroxidase in fungi. Experientia 29. $381-387$

HatakKa, A. \& Tervila-Wilo, A. (1986). Ligninases of white-rot fungi. In Proceedings of Soviet and Finnish Seminar on Microbial Degradation of Lignocellulose. Raw Materials, 1985 (Tbilisi, Georgia. USSR), pp. 65-74. Pushchino, USSR: USSR Academy of Sciences.

Hatakka, A. I. \& Uusi-Rauva, A. K. (1983). Degradation of ${ }^{14} \mathrm{C}$ labelled poplar wood lignin by selected white-rot fungi. European Journal of Applied Microbial Biotechnology 17, 235-242.

Hedlund, K., Boddy, L. \& Preston, C. M. (1991). Mycelial responses of the soil fungus Mortierella isabellina to grazing by Onychiurus armatus (Collembola). Journal of Soil Biology and Biochemistry 23, 361-366..

HiNTIKKA, V. \& KORHONEN, K. (1970). Effects of carbon dioxide on the growth of lignicolous and soil-inhabiting Hymenomycetes. Communicationes Instituti Forestalis Fenniae 62, 1-22.

HioRTH, J. (1965). The phenoloxidase and peroxidase activities of two culture types of Phellinus tremulae (Bond.) Bond. \& Boriss. Meddeleser Norske Skoforsoksvesen 20, 249-272.

JENNINGS, D. H. (1988). Inorganic nutrition. In Physiology of Industrial Fungi, pp. 77-96. Edited by D. R. Berry. Oxford: Blackwell Scientific Publications.

Jonsson, L., Johansson, T., Sjostrom, K. \& Nyman, P. O. (1987) Purification of ligninase isozymes from white-rot fungus Trametes versicolor. Acta Chemica Scandinavica B41, 766-769.

KAARIK, A. (1965). The identification of the mycelia of wood-decay fungi by their oxidation reactions with phenolic compounds. Studia Forestalia Suecica 31

Kantelinen, A., Hatakka, A. \& Vilkari, L. (1989). Production of lignin peroxidase and laccase by Phlebia radiata. Applied Microbiology and Biotechnology 31, 234-239.

Katayama, Y., Nishida, T., Morohoshi, N. \& Kuroda, K. (1989). The metabolism of biphenyl structures in lignin by the wood-rotting fungus Coriolus versicolor. FEMS Microbiology Letters 61, 307-314.

KIRK, T. K. \& FarReLl, R. L. (1987). Enzymatic 'combustion': the microbial degradation of lignin. Annual Review of Microbiology 41, 465-505.

KIRKPaTRICK, N. \& PALMer, J. M. (1989). A natural inhibitor of lignin peroxidase activity from Phanerochaete chrysosporium, active at low $\mathrm{pH}$ and inactivated by divalent metal ions. Applied Microbiology and Biotechnology 30, 305-311. 
KoENIGS, J. W. (1974). Hydrogen peroxide and iron: a proposed system for decomposition of wood by brown-rot basidiomycetes. Wood Fiber 6, 66-79.

Leatham, G. F. \& StahmanN, M. A. (1981). Studies on the laccase of Lentinus edodes: specificity, localization and association with the development of fruiting bodies. Journal of General Microbiology 125, 147-157.

LEVINE, W. A. (1965). Laccase, a review. In The Biochemistry of Copper, pp. 371-387. Edited by J. Peisach, P. Aisen \& W. E. Blumberg. New York: Academic Press.

LoNG, T. J. \& AlBEN, J. O. (1978). Preliminary studies of mushroom tyrosinase. Mushroom Science 7, 69-79.

LUNDQUIST, K. \& KRISTERSSON, P. (1985). Exhaustive laccasecatalysed oxidation of a lignin model compound (vanillyl glycol) produces methanol and polymeric quinoid products. Biochemical Journal 229, 277-279.

Mayer, A. M. \& Harel, E. (1979). Polyphenol oxidases in plants. Phytochemistry 18, 193-215.

MetzleR, D. E. (1977). Biochemistry, pp. 571-637. Ames: Iowa State University Press.

Molitoris, H. P. (1978). Wood degradation, phenoloxidases and chemotaxonomy of higher fungi. Mushroom Science 10, 243-263.

Morohoshi, N., Nakamura, M., Katayama, Y., Haraguchi, T., FujII, T. \& Hirol, T. (1989). Degradation of protolignin by laccase III. International Biodeterioration 25, 7-14.

MORPETH, F. F. \& JONES, G. D. (1986). Resolution, purification and some properties of the multiple forms of cellobiose quinone dehydrogenase from the white-rot fungus Phanerochaete chrysosporium. Biochemical Journal 236, 221-226.

Moss, M. O. (1984). The mycelial habit and secondary metabolite production. In The Ecology and Physiology of the Fungal Mycelium, pp. 127-142. Edited by D. H. Jennings \& A. D. M. Rayner. Cambridge: Cambridge University Press.

Niemela, T. (1977). The effect of temperature on two culture types of Phellinus tremulae (Fungi, Hymenochaetaceae). Annales Botanici Fennici 14, 21-24.

Niku-Paavola, M.-J., Karhunen, E., Salola, P. \& Raunio, V. (1988). Ligninolytic enzymes of the white-rot fungus $P$ hlebia radiata. Biochemical Journal 254, 877-884.

NoBles, N. K. (1965). Identification of cultures of wood-inhabiting hymenomycetes. Canadian Journal of Botany 43, 1097-1139.

Paterson, A. (1988). Fungal enzymes. In Physiology of Industrial Fungi, pp. 101-129. Edited by D. R. Berry. Oxford: Blackwell Scientific Publications.

Poppe, J. \& WelvaerT, W. (1983). Identification of Hymenomycetes in pure-culture by characterization of their mycelia and trials for artificial fructification. Mededelingen van de Faculteit Ladbouwwetenschappen Rijksuniversiteit Gent 48, 901-912.

Prillinger, H. J. \& Molitoris, H. P. (1981). Praktische Bedeutung von Enzymspektren bei Pilzen. Der Champignon 233, 28-34.
Rayner, A. D. M. \& CoAtes, D. (1987). Regulation of mycelial organization and responses. In Evolutionary Biology of the Fungi, pp. 115-136. Edited by A. D. M. Rayner, C. M. Brasier \& D. Moore. Cambridge: Cambridge University Press.

Rayner, A. D. M., Boddy, L. \& Dowson, C. G. (1987). Genetic interactions and developmental versatility during establishment of decomposer basidomycetes in wood and tree litter. In Ecology of Microbial Communities, pp. 83-123. Cambridge : Cambridge University Press.

SCHANEL, L. (1976). Role of carbon dioxide in growth and decaying activity of wood-rotting fungi. Folia Facultatis Scientarium Naturalium Universitatis Purkyninae Brunensis 54, 5-53.

Sharland, P. R., Burton, J. L. \& RaYNer, A. D. M. (1986). Mycelial dimorphism, interactions and pseudosclerotial plate formation in Hymenochaete corrugata. Transactions of the British Mycological Society 86, 158-163.

STALPERS, J. A. (1978). Identification of wood-inhabiting fungi in pure culture. Studies in Mycology 16, 1-248.

TABAK, H. H. \& COOKE, B. (1968). The effects of gaseous environments on the growth and metabolism of fungi. Botanical Review 34, 126252.

Thompson, W. \& RAYNER, A. D. M. (1982). Structure and development of mycelial cord systems of Phanerochaete laevis in soil. Transactions of the British Mycological Society 78, 193-200.

Vermousek, I. \& Schanel, L. (1973). White-rot fungus Pleurotus ostreatus as a new source of peroxidase and glucose oxidase. Ninth International Congress of Biochemistry 41, 68.

WeLlS, J. \& BODDY, L. (1990). Wood decay, and phosphorus and fungal biomass allocation, in mycelial cord systems. New Phytologist 116, 285-295.

Wessels, J. G. H. (1991). Fungal growth and development : a molecular perspective. In Frontiers in Mycology. Honorary and General Lectures from the Fourth International Mycological Congress, Regensberg 1990 , pp. 27-48. Edited by D. L. Hawksworth. Wallingford: CAB International Press.

WhITE, N. A. (1992). Biotechnological implications of the ecology and developmental biology of selected higher fungi. $\mathrm{PhD}$ thesis, University of Wales College of Cardiff.

Wood, D. A., Perry, C., Thurston, C. F., Matcham, S. E., Dudley, K., Claydon, N. \& Allan, M. (1990). Molecular analysis of lignocellulolytic enzymes of the edible mushroom Agaricus bisporus. In Biotechnology in Pulp and Paper Manufacture, pp. 659-666. Edited by T. K. Kirk \& H.-M. Chang. Stoneham, MA: ButterworthHeinemann.

Wosten, H. A. B., Moukha, S. M. \& Wessels, J. G. H. (1990), Localization of protein secretion in filamentous fungi. Fourth International Mycological Congress (Abstracts), Regensberg, Germany B, 101 .

Westermark, U. \& ERIKsson, K. E. (1974). Cellobiose :quinone oxidoreductase, a new wood degrading enzyme from white-rot fungi. Acta Chemica Scandinavica B28, 209-214. 